\title{
Positional Effect of $\pi$-extension in Triple Helicenes
}

Alex van der Ham, ${ }^{[a]}$ Thomas Hansen, ${ }^{[a, b]}$, Herman S. Overkleeft, ${ }^{[a]}$ Trevor A. Hamlin, ${ }^{[b]}$ Dmitri V. Filippov, ${ }^{*[a]}$ and Grégory F. Schneider*[a]

[a] A. van der Ham, Dr. T. Hansen, Dr. D. V. Filippov, Prof. Dr. H. S. Overkleeft, and Dr. G. F. Schneider Leiden Institute of Chemistry, Leiden University, Einsteinweg 55, 2333 CC Leiden (The Netherlands)

* e-mail: g.f.schneider@chem.leidenuniv.nl

*e-mail: filippov@chem.leidenuniv.nl

[b] Dr. T. Hansen and Dr. T. A. Hamlin

Department of Theoretical Chemistry, Amsterdam Institute of Molecular and Life Sciences (AIMMS),

Amsterdam Center for Multiscale Modeling (ACMM), Vrije Universiteit Amsterdam, De Boelelaan 1083, 1081

HV Amsterdam (The Netherlands)

\section{ABSTRACT}

The targeted application of multiple helicenes in photo-optical applications requires their rational design. Toward this goal, we report on the synthesis of pyrene-based triple helicene 1 and investigate the positional effect of extension of the $\pi$-conjugated system on the photo-chemical and chiro-optical properties of triple helicenes. The conformational and aggregatory behavior of 1 were studied both experimentally using VT NMR spectroscopy and computationally using high-level DFT computations. Although $\pi$-extension was observed to have a marked effect on the spectroscopic properties of triple helicenes, comparison with other known $\pi$-extended helicenes reveals that the position at which $\pi$ extension is introduced is only of nominal importance. Our results thus suggest that the presence of a particular helicene motif is dominant in dictating the physico-chemical properties of triple helicenes. 


\section{Introduction}

Helicenes are a subclass of non-planar polycyclic aromatic hydrocarbons (PAHs) consisting of an array of ortho-fused benzene rings, that adopt a helical geometry. Despite showing interesting physicochemical properties, their application in, e.g., chirality sensing, ${ }^{[1]}$ asymmetric catalysts, ${ }^{[2]}$ and chiro-optical materials is ultimately hampered due to their low photo-stability and low barriers for racemization. ${ }^{[3]}$ Several recent syntheses of molecules that feature the helicene motif have circumvented the aforementioned shortcomings. These approaches include the fusion of additional benzene rings into socalled $\pi$-extended helicenes, ${ }^{[4]}$ as well as the merger of multiple helicene motives into a single molecule, yielding double, ${ }^{[5]}$ triple, ${ }^{[6]}$ and even quadruple helicenes (Scheme 1). ${ }^{[7]}$ Of these, the triple helicenes, which we call propellerenes, are of particular interest, with hexabenzotriphenylene (HBT), i.e., showing the highest dichroism dissymmetry factor of all known helicenes and helicinoids. ${ }^{[8]}$

As the photo-optical properties of aromatic molecules are driven by the size of the conjugated system, their relationship provides an important guiding principle for the rational design of photooptical materials. ${ }^{[9]}$ Yet, although such relationships have been well documented for monohelicenes ${ }^{[10]}$ and multiple helicenes, ${ }^{[11]}$ a systematic study on the effect of $\pi$-extension on the properties of helicenes vis-à-vis propellerenes is, to the best of our knowledge, lacking in the literature. We have, therefore, synthesized the $\pi$-extended, tripyrenylene 1 , to study both the effect of $\pi$-extension on the photo-optical properties of propellerenes and the importance of the position of the $\pi$-extension.

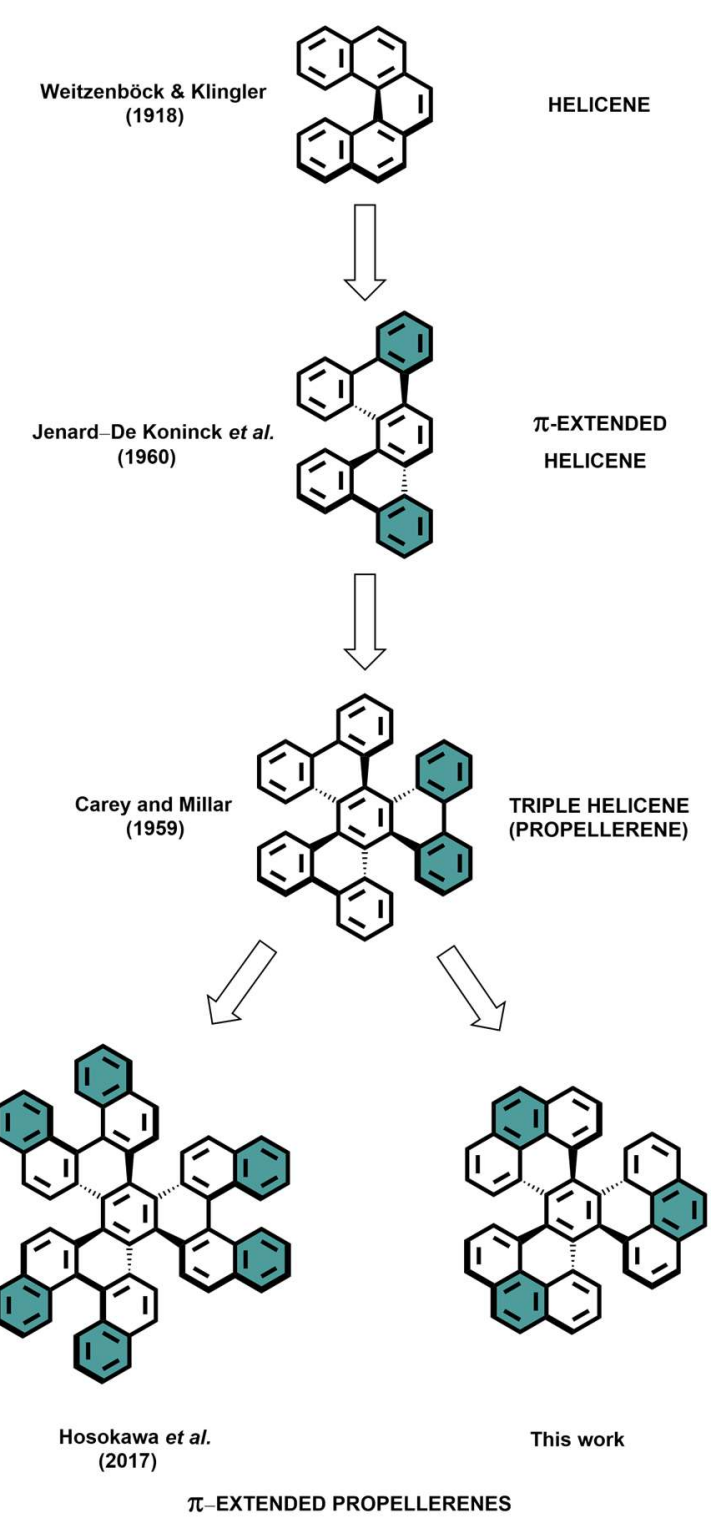

Scheme 1. Schematic representation of the increased rigidification of a helicene structure. Names and dates given are those related to the first identification of the compound.

\section{Results and Discussion}

Synthesis. The most common approach to synthesize triphenylenes class propellerenes is via the palladium $(0)$ catalyzed $[2+2+2]$ cycloaddition of arynes. ${ }^{[12]}$ Because of the reactive nature of these arynes, they are generated in situ, often from the treatment of an ortho-TMS triflate with a fluoride source. As such, for the present target molecule, we required ortho-TMS triflate $\mathbf{5}$, which in turn required us to obtain sizable quantities of 4-hydroxypyrene $\mathbf{3}$ (Scheme 2A). Synthesis of $\mathbf{3}$ is not straightforward, as selective derivatization of pyrene on the C-4 position poses a serious synthetic challenge. Recently, a synthetic procedure to obtain $\mathbf{3}$ was reported which involves reduction of pyrene to $1,2,3,6,7,8$-hexahydropyrene followed by bromination on the desired position, substitution with methoxide and finally demethylation. ${ }^{[13]}$ Although this, and other procedures, yield the desired compound, they all suffer from either several steps or unsatisfactory overall yield. ${ }^{[14]}$ We were able to successfully synthesize $\mathbf{3}$ in 50\% yield via a Tiffeneau-Demjanov-like reaction by treatment of 4-oxocyclopenta[def]phenanthrene $\mathbf{2}$ with TMS-azido methane in the presence of $\mathrm{BF}_{3}$ etherate. An efficient gram scale, two-step synthesis of $\mathbf{2}$ from pyrene was recently published by us. ${ }^{[15]}$ Bromination of $\mathbf{3}$ proved cumbersome and was ultimately only found possible using elemental bromine in $\mathrm{CS}_{2}$ at low temperatures. A three-step-one-pot procedure involving ortho-lithiation, retro-Brook rearrangement 
and quenching of the resultant phenolate with triflic anhydride then afforded ortho-TMS triflate $\mathbf{5}$ in an overall yield of $47 \%$. Treatment of 5 with CsF in the presence of a palladium(0) catalyst then afforded propellerene 1 in $47 \%$ yield. Propellerene 1 incorporates three $\pi$-extended [5] helicene motives, with one shared central six-membered ring. Like all propellerenes, 1 can exist in either a $C_{2}$ or $D_{3}$ conformation, depending on the molecular symmetry, and each helix can be labelled depending on its relative chirality as either $\mathrm{P}$ (for plus) or $\mathrm{M}$ (for minus) (Scheme $2 \mathrm{~B}$, also see Scheme 3 ).

a)
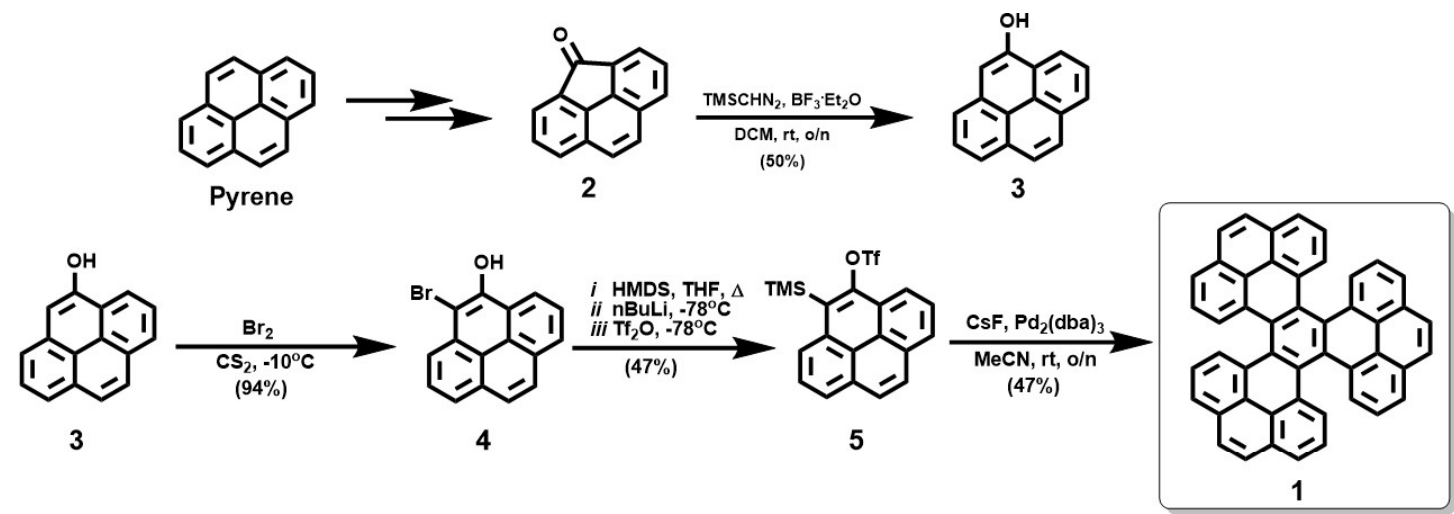

b)

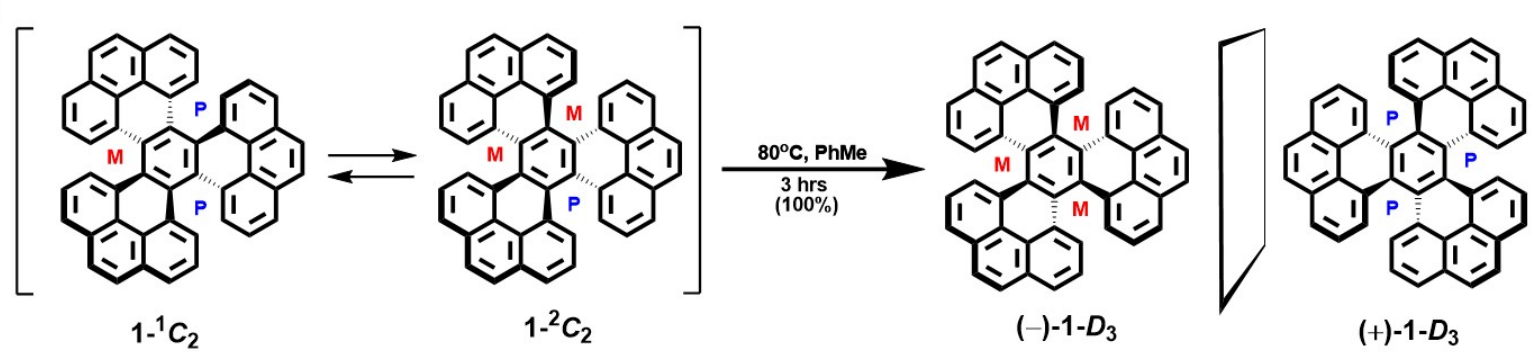

Scheme 2. a) Synthesis of 4-hydroxypyrene 3 and $\pi$-extended tripyrenylene 1 therefrom. b) Schematic representation of the interconversion of the two enantiomers of 1- $C_{2}$ and $1-D_{3}$, and the conversion between the two conformers.

Kinetics and VT-NMR. To determine the conformation of the isolated tripyrenylene $\mathbf{1}$, variable temperature NMR experiments in toluene- $d_{8}$ were performed (Figure $1 \mathrm{~A}$; also see $\mathrm{SI}$ ). At room temperature, the ${ }^{1} \mathrm{H}$ spectrum of 1 only shows four resonances due to rapid interconversion between its two $C_{2}$ conformations. When cooled to $-90^{\circ} \mathrm{C}$, however, interconversion is no longer possible and additional resonances are observed, corresponding to protons on the individual wings of the propellerenes (note that the two conformers are both chemically and magnetically equivalent and thus their resonances coincide). The coalescence temperature for the interconversion between the two $C_{2}$ conformers was found to be approximately $-90{ }^{\circ} \mathrm{C}$ (Fig. 1), corresponding to a barrier height to interconversion of $10.0 \mathrm{kcal} \mathrm{mol}^{-1}$, which is in excellent agreement with the value of $9.9 \mathrm{kcal} \mathrm{mol}^{-1}$ computed at SMD(Toluene)-PBE-D3(BJ)/6-31G(d,p). Heating of the solution to $80^{\circ} \mathrm{C}$ (in toluene- $d_{8}$ ) resulted in conversion of $1-C_{2}$ to its $D_{3}$ conformer. This was evidenced by the disappearance of the original 1- $C_{2}$ resonances, with a half time of approximately 20 mins., corresponding to a barrier height of $\Delta G^{\ddagger}=26.0 \mathrm{kcal} \mathrm{mol}^{-1}$, and which is in equally good agreement with the computed value of $25.8 \mathrm{kcal}$ $\mathrm{mol}^{-1}$, also computed at SMD(Toluene)-PBE-D3(BJ)/6-31G(d,p) (Fig. 2). It was observed that conversion of 1- $C_{2}$ to $1-D_{3}$ conformer was accompanied by precipitation of the compound, due to a significantly worse solubility of the compound this conformation, resulting in a decrease in absolute signal intensity. This could be attributed to a better stacking of the $D_{3}$ conformer, due to its lesser degree of distortion from planarity, compared to the $C_{2}$ conformer. Indeed, the intermolecular distances in the dimers were 
computed to be 4.5 and $4.4 \AA$ for the $C_{2}$ and $D_{3}$ dimer respectively (SI Fig. S1). Computation of the dimerization energies for $1-C_{2}$ and $1-D_{3}$ gave values of -21.9 and $-24.4 \mathrm{kcal} \mathrm{mol}^{-1}$ respectively, corroborating this observation (SI S9 and S10). Cooling of a solution of $1-D_{3}$ to $-80^{\circ} \mathrm{C}$ no longer resulted in a change in the number of observed resonances, confirming 1 to now reside in the $D_{3}$ conformation.

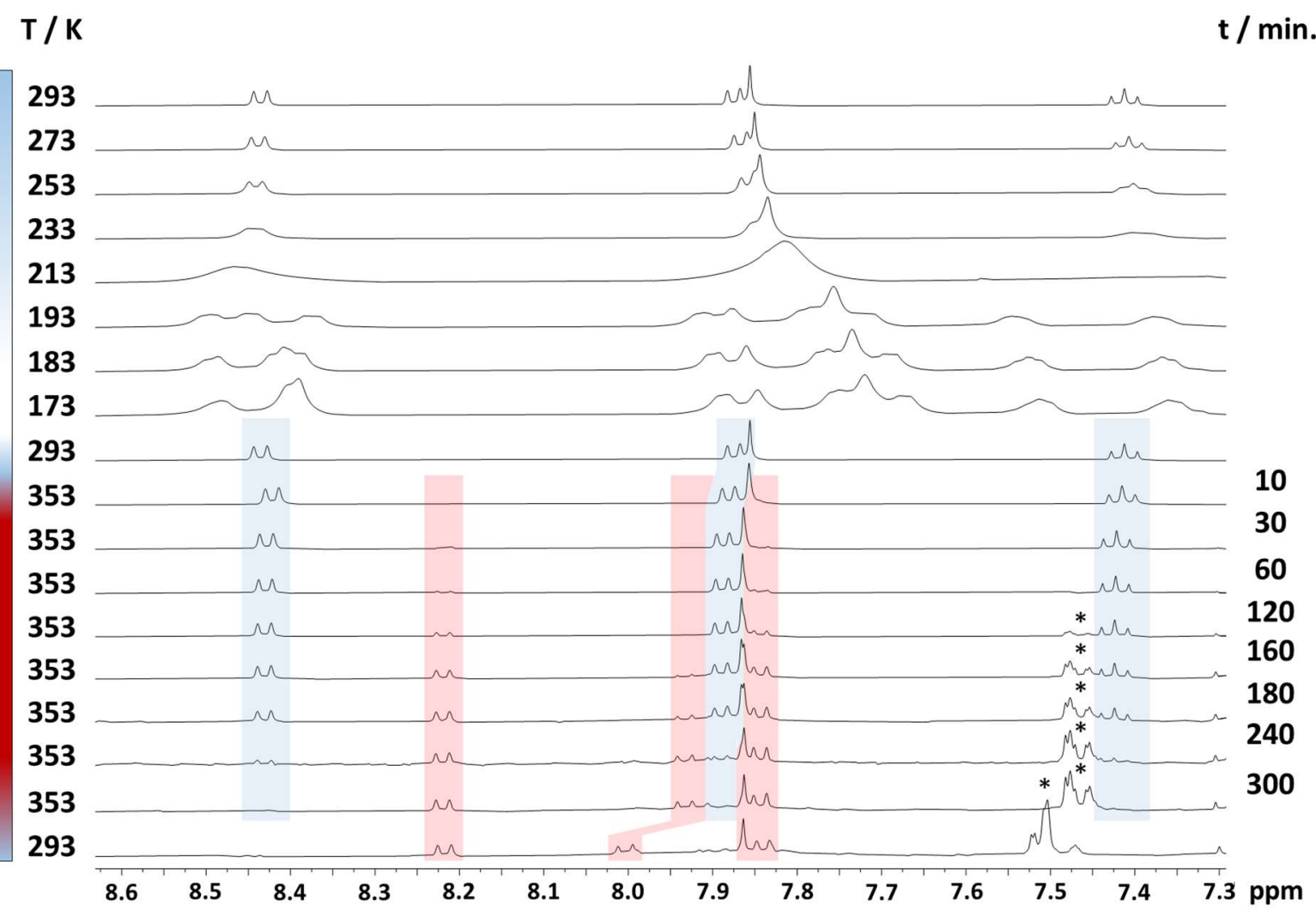

Figure 1. ${ }^{1} \mathrm{H}$ VT-NMR spectra of 1 in Tol- $d_{8}$. Spectra are arbitrarily scaled for clarity. Resonances marked by asterisks originate from the solvent. Resonances shaded in blue and red belong to the $C_{2}$ and $D_{3}$ conformer respectively.

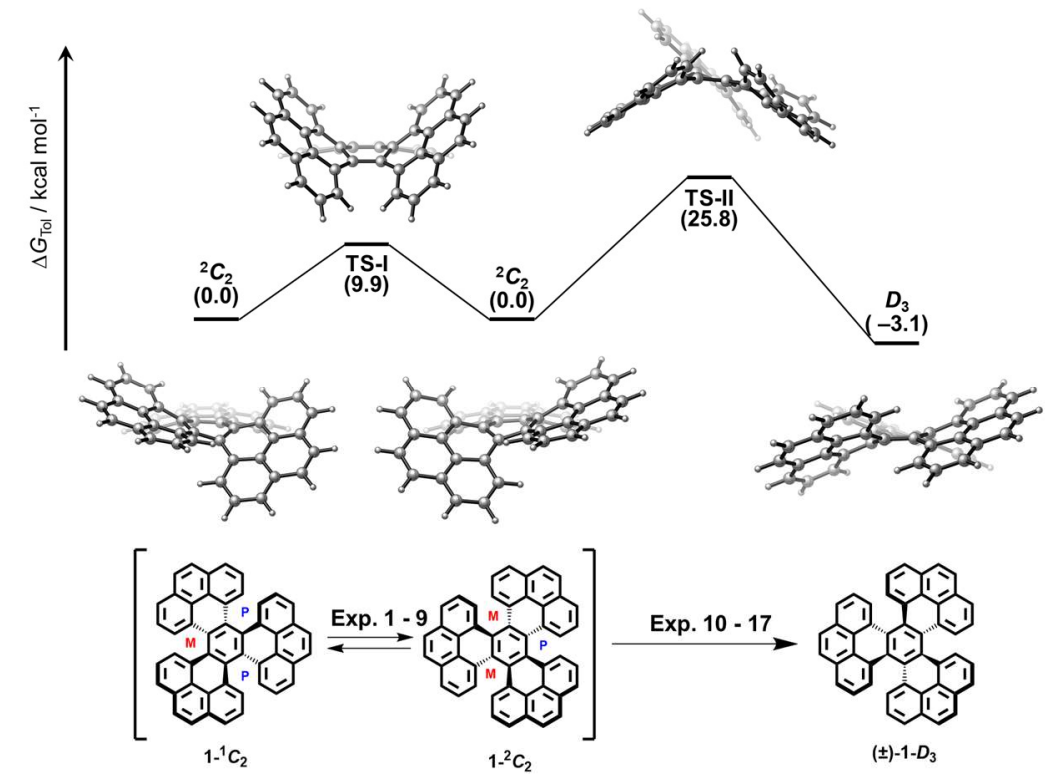

Figure 2. Potential energy surface and schematic representation of the interconversion of 1- $C_{2}$ and 1- $D_{3}$ the and the interconversion of the two 1- $C_{2}$ enantiomers, as observable by VT-NMR. Gibbs free energies (in $\mathrm{kcal}^{\mathrm{mol}}{ }^{-1}$ ) were computed at the SMD(Toluene)-PBE-D3(BJ)/6-31G(d,p) level. 
Kinetic control. Formation of the thermodynamically less favorable $C_{2}$ conformers in the palladium(0) catalyzed trimerization of arynes has previously been reported. ${ }^{[16]}$ To understand whether this kinetic control is substrate dependent or independent, and to determine at what point the $C_{2}$ symmetry is introduced, we computed the entire potential energy surface (PES) of this reaction. The PES for the synthesis of hexabenzotriphenylene HBT was chosen as model system, ${ }^{[17]}$ for which the kinetic effect was first reported. The PES was computed starting from the step-wise coordination of two phenanthryne units to palladium(0), which was found to be exergonic by -69.0 and then $-34.2 \mathrm{kcal}$ $\mathrm{mol}^{-1}$ (Fig. 3). Kamikawa et al. recently showed that the energies accompanying solvent association to and dissociation from the palladium center are negligible relative to the other processes along the reaction coordinate $\left(\sim 1.5 \mathrm{kcal} \mathrm{mol}^{-1}\right)$, and were thus not considered here. ${ }^{[18]}$ Ligands were disregarded for the same reason. ${ }^{[19]}$ The formation of diene P3 proceeds via TS-I, whose energy barrier for formation was found to be $23.6 \mathrm{kcal} \mathrm{mol}^{-1}$. For the trimerization of benzyne, the corresponding diene has a $C_{2 v}$ symmetry, ${ }^{[20]}$ whereas steric clash between the spatially proximal rings in palladacycle $\mathbf{P} \mathbf{3}$ results in the adaptation of a non-planar $C_{2}$ geometry. Coordination of a third phenanthryne to diene $\mathbf{P 3}$ results in a further $17.4 \mathrm{kcal} \mathrm{mol}^{-1}$ lowering in free Gibbs energy, to yield reaction intermediate $\mathbf{P 4}$. It is of interest to note that this phenanthryne unit in $\mathbf{P 4}$ is oriented perpendicularly to the diene plane, which already alludes to the way in which it will insert itself into the complex. ${ }^{[21]}$ Namely, the addition of the third phenanthryne unit to the diene was found to proceed via a two-step insertion mechanism. First, a seven-membered intermediate is formed via TS-II at $13.2 \mathrm{kcal} \mathrm{mol}^{-1}$ yielding intermediate P5. This is then followed by the concomitant formation of the final $\mathrm{C}-\mathrm{C}$ bond and reductive elimination of the palladium center via a slightly lower transition state TS-III at $12.7 \mathrm{kcal} \mathrm{mol}^{-1}$ to give reaction complex P6. Like others before us, ${ }^{[6 a]}$ we were unable to locate a TS that describes a concerted [4 + 2] cycloaddition, i.e. a canonical Diels-Alder addition. A constrained PES was therefore constructed in which bond forming C...C distances were artificially constrained to be synchronously concerted (SI Figure S6). Although the initial products of both PESs are different, the energetic maximum of the concerted synchronous reaction was approximately $25 \mathrm{kcal} \mathrm{mol}^{-1}$ more endergonic with respect to the TS of the step-wise addition (i.e. TS-II at $\Delta G^{\ddagger}=13.6 \mathrm{kcal} \mathrm{mol}^{-1}$ ). This is attributable to a much less favorable orbital alignment, steric clash and the requirement for an unfavorable dearomatization of the palladacyclic complex. Regardless of the exact mechanism, the $C_{2}$ symmetry of the reaction product is introduced at this point along the PES, and is asserted to be substrate independent. 
a)

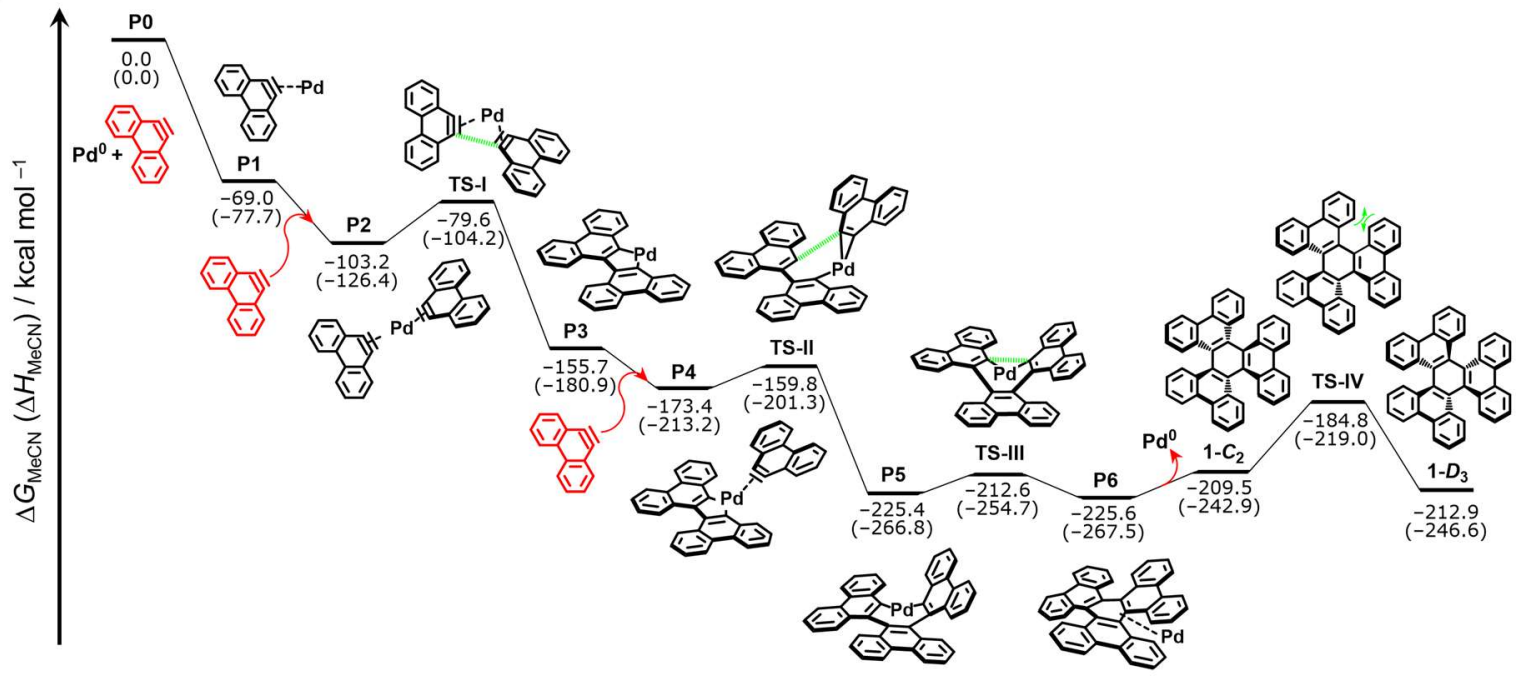

b)

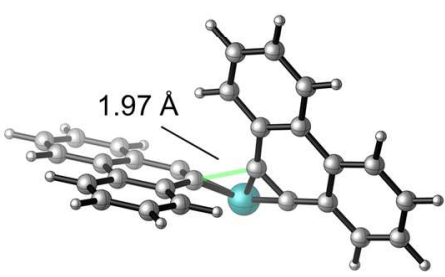

TS-I

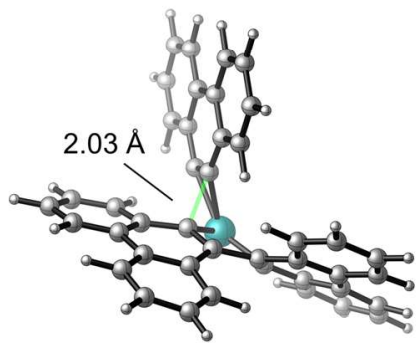

TS-II

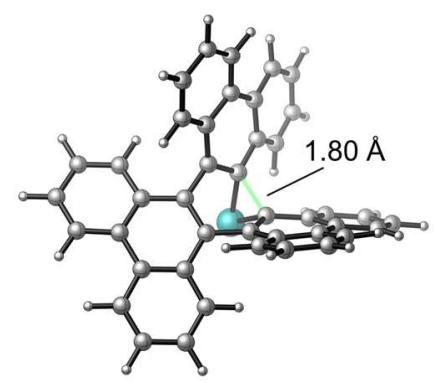

TS-III

Figure 3. a) The potential energy surface of the palladium(0) catalyzed trimerization of phenanthren-9,10-yne. Gibbs free energies and enthalpies are computed at the SMD(MeCN)-PBE-D3(BJ)/6-31G(d,p) level of theory are given in $\mathrm{kcal} \mathrm{mol}^{-1}$. b) Transition state structures with key interatomic distances given in Ångstroms.

Photo-physical properties. As the $C_{2}$ and $D_{3}$ conformer of 1 can be separately isolated, the properties of the individual conformers could be studied separately (Fig. 4a). Both conformers yield yellow solutions in chloroform under ambient light, and show green under UV light $\left(\lambda_{\text {ex. }}=254 \mathrm{~nm}\right)$. The UV$V$ is spectrum of $1-C_{2}$ shows an onset at $504 \mathrm{~nm}$, corresponding to an optical band gap of $2.46 \mathrm{eV}$. Weak shoulders are observed at $439 \mathrm{~nm}$ and $416 \mathrm{~nm}$, which were computed using time dependent (TD) DFT at the $\mathrm{SMD}\left(\mathrm{CHCl}_{3}\right)-\mathrm{B} 3 \mathrm{LYP} / 6-311+\mathrm{G}(2 \mathrm{~d}, \mathrm{p}) / / \mathrm{B} 3 \mathrm{LYP}-\mathrm{D} 3(\mathrm{BJ}) / 6-31 \mathrm{G}(\mathrm{d}, \mathrm{p})$ level, to correspond to the HOMO $\rightarrow$ LUMO transition ( $\lambda_{\text {calc }}=436 \mathrm{~nm}, f=0.0179 ; \lambda_{\text {calc }}=466 \mathrm{~nm}, f=0.1099$ ), as well as mixtures of different frontier orbital transitions. Two local maxima are found at $385 \mathrm{~nm}$ and $365 \mathrm{~nm}$, with a global maximum is located at $295 \mathrm{~nm}\left(\varepsilon_{\max , \mathrm{C} 2}=3.05 \times 10^{4} \mathrm{~mol}^{-1} \mathrm{~L} \mathrm{~cm}^{-1}\right)$. The spectrum of 1- $D_{3}$ is distinctly different to that of $1-C_{2}$. The absorption onset is slightly red shifted compared to that of $1-C_{2}$ at $522 \mathrm{~nm}$, corresponding to an optical band gap of $2.37 \mathrm{eV}$. Absorption bands are found at $506 \mathrm{~nm}$ and $473 \mathrm{~nm}$, corresponding respectively to the HOMO $\rightarrow$ LUMO $+1\left(\lambda_{\text {calc }}=493 \mathrm{~nm}, f=0.0000\right)$ and a mixed HOMO $\rightarrow$ LUMO $/ \mathrm{HOMO}-1 \rightarrow$ LUMO+1 $\left(\lambda_{\text {calc }}=448 \mathrm{~nm}, f=0.3454\right)$ transition. A single local maximum is found at $394 \mathrm{~nm}$ with the global maximum located at $282 \mathrm{~nm}\left(\varepsilon_{\max , \mathrm{D} 3}=2.83 \times 10^{4} \mathrm{~mol}^{-1} \mathrm{~L} \mathrm{~cm}^{-1}\right)$. Comparison of the UV-Vis spectra of 1 to that of [5]helicene, ${ }^{[22]}$ dibenzo[f,j]picene, ${ }^{[23]}$ and HBT (Figure S5), reveals that an increase of conjugation results in a bathochromic broadening of the UV-Vis spectrum, as well as a bathochromic shift of the initial (higher wavelength) absorption maximum. Comparison of the UVVis spectrum of 1 to that of hexapole [5] helicene of Hosokawa et al. shows only minimal differences, ${ }^{[6]}$ suggesting that, although increased $\pi$-conjugation results in a noticeable change in spectroscopic 
properties, the location of at which this increased conjugation is introduced is only of nominal importance.

a)

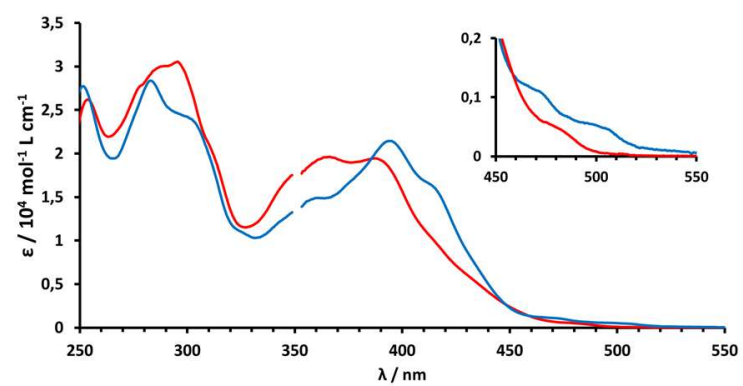

b)

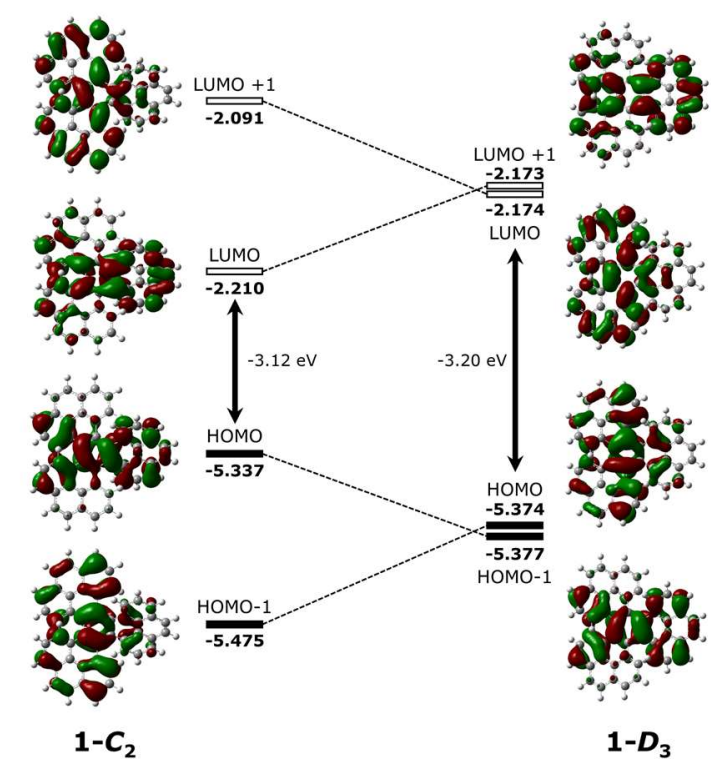

Figure 4. a) UV-Vis spectrum of $1-C_{2}$ (red) and $1-D_{3}$ (blue) in chloroform ( $c=3.149 \times 10^{-5}$ and $3.000 \times 10^{-5} \mathrm{M}$ respectively). Inset: $450-550 \mathrm{~nm}$. The gap around 350 $\mathrm{nm}$ is due to switching of the lamp. b) Energy diagram of the frontier orbitals of 1- $C_{2}$ and $1-D_{3}$ computed at TD DFT $\quad \mathrm{SMD}\left(\mathrm{CHCl}_{3}\right)-\mathrm{B} 3 \mathrm{LYP} / 6-311+\mathrm{G}(2 \mathrm{~d}, \mathrm{p}) / / \mathrm{B} 3 \mathrm{LYP}-$ $\mathrm{D} 3(\mathrm{BJ}) / 6-31 \mathrm{G}(\mathrm{d}, \mathrm{p})$. Phases are arbitrarily colored.
Frontier orbitals. The semblance of the UV-Vis spectra of $\mathbf{1}$ vis-à-vis hexapole [5]helicene suggested a corresponding similarity of the underlying molecular orbital structure. Thus, the frontier orbitals of both conformers of 1 were computed using TD-DFT at the $\operatorname{SMD}\left(\mathrm{CHCl}_{3}\right)$ B3LYP/6-311+G(2d,p)//B3LYP-D3(BJ)/6-31G(d,p) level of theory, and compared. The HOMOs and LUMOs in both conformations are found to be an expected $\pi$ and $\pi^{*}$-type respectively. The HOMO/HOMO -1 and LUMO/LUMO +1 pairs are distinguishable by the presence of MOs on either one or two of the $K$-regions of the pyrene moieties respectively (Fig. 4b). This feature allows tracking of the frontier orbitals during the $C_{2} \rightarrow D_{3}$ conversion. It is observed that, during this transition, the HOMO of 1- $C_{2}$ becomes more stabilized, whereas the LUMO becomes more destabilized, yielding the HOMO -1 and LUMO +1 in $1-D_{3}$ respectively. Concomitantly, the HOMO -1 and LUMO +1 of $1-C_{2}$ become more and less destabilized respectively, yielding the HOMO and LUMO of $1-D_{3}$. The net result is a widening of the band gap from $-3.12 \mathrm{eV}$ to -3.20 eV. Interestingly, HBT was computed to show the same behavior (Fig. S2 and S3), and which has also been reported for hexapole [5]helicene. ${ }^{[6]}$ This suggests this "frontier orbital cross-over effect" to be a general feature of benzenoid triphenylenes, and is suspected to be the result of the greater planarity of propellerenes in their $D_{3}$ conformation (cq. Fig. S1).

For completeness, computation of the FMOs of [5]helicene and dibenzo[f,j]picene revealed a clear correlation between $\pi$-extension and size of the HOMO - LUMO gap, with an increase and decrease in the HOMO and LUMO energy respectively, when going from [5] helicene to 1 and hexapole [5]helicene (Fig. S4); supporting the bathochromic shift observed in their UV-Vis spectra (Fig. S5). ${ }^{[24]}$

\section{Conclusion}

To conclude, we here reported the synthesis of the $\pi$-extended propelleren tripyrenylene 1 by the palladium(0) catalyzed [2+2+2] cyclization of in situ generated pyren-4,5-yne. The compound was isolated at the thermodynamically less stable $C_{2}$ conformer. Interconversion of 1 between its two $C_{2}$ 
enantiomers and conversation to a $D_{3}$ conformer were followed by VT-NMR, with experimental results showing good agreement with those obtained by DFT computations. Moreover, the origin of the kinetic control of this reaction was investigated by computing the PES of this reaction, which showed it to be substrate independent. The photo-optical properties of both conformers of $\mathbf{1}$ were studied by $U V$-Vis, and showed large similarities to known $\pi$-extended propellerenes. Frontier orbitals were computed using TD DFT and showed a characteristic crossing of the frontier orbitals during the $C_{2} \rightarrow$ $D_{3}$ transition. The large similarity between the photo-optical properties of tripyrenylene 1 compared to known propellerenes hexabenzotriphenylene and hexapole [5]helicene, indicates that, although $\pi$ extension has a noticeable effect on the physico-chemical properties of propellerene molecules, the position at which additional benzene rings are added is of only nominal importance. These results therefore suggest that the helicene motives are dominant in determining the physico-chemical properties of this class of chiral, non-planar PAHs.

\section{References}

[1] a) M. Hasan, V. Borovkov, Symmetry 2018, 10, 10; b) G. A. Hembury, V. V. Borovkov, Y. Inoue, Chem. Rev. 2008, 108, 1-73; c) Y. Yang, R. C. Da Costa, M. J. Fuchter, A. J. Campbell, Nat. Photonics 2013, 7, 634-638.

[2] a) K. Yamamoto, T. Shimizu, K. Igawa, K. Tomooka, G. Hirai, H. Suemune, K. Usui, Sci. Rep. 2016, 6, 1-8; b) P. Aillard, A. Voituriez, A. Marinetti, Dalton T. 2014, 43, 15263-15278; c) 0. Stetsovych, M. Švec, J. Vacek, J. V. Chocholoušová, A. Jančařík, J. Rybáček, K. Kosmider, I. G. Stará, P. Jelínek, I. Starý, Nat. Chem. 2017, 9, 213-218.

[3] a) H. Isla, J. Crassous, Compt. Rend. Chim. 2016, 19, 39-49; b) J. Bosson, J. Gouin, J. Lacour, Chem. Soc. Rev. 2014, 43, 2824-2840.

[4] a) M. Buchta, J. Rybáček, A. Jančařík, A. A. Kudale, M. Buděšínský, J. V. Chocholoušová, J. Vacek, L. Bednárová, I. Císařová, G. J. Bodwell, Chem. Eur. J. 2015, 21, 8910-8917; b) Y. Nakakuki, T. Hirose, H. Sotome, H. Miyasaka, K. Matsuda, J. Am. Chem. Soc. 2018, 140, 4317-4326; c) P. J. Evans, J. Ouyang, L. Favereau, J. Crassous, I. Fernández, J. Perles, N. Martín, Angew. Chem. Int. Ed. 2018, 57, 6774-6779; d) C. M. Cruz, S. Castro-Fernández, E. Maçôas, J. M. Cuerva, A. G. Campaña, Angew. Chem. Int. Ed. 2018, 57, 14782-14786; e) Y. Hu, G. M. Paternò, X.-Y. Wang, X.-C. Wang, M. Guizzardi, Q. Chen, D. Schollmeyer, X.-Y. Cao, G. Cerullo, F. Scotognella, J. Am. Chem. Soc. 2019, 141, 12797-12803.

[5] a) F. Chen, T. Tanaka, Y. S. Hong, T. Mori, D. Kim, A. Osuka, Angew. Chem. 2017, 129, 1488014885 ; b) S. Hashimoto, S. Nakatsuka, M. Nakamura, T. Hatakeyama, Angew. Chem. Int. Ed. 2014, 53, 14074-14076; c) D. Sakamaki, D. Kumano, E. Yashima, S. Seki, Angew. Chem. 2015, 127, 5494-5497; d) M. Ferreira, G. Naulet, H. Gallardo, P. Dechambenoit, H. Bock, F. Durola, Angew. Chem. Int. Ed. 2017, 56, 3379-3382; e) H. Tanaka, M. Ikenosako, Y. Kato, M. Fujiki, Y. Inoue, T. Mori, Commun. Chem. 2018, 1, 1-8; f) X. Liu, P. Yu, L. Xu, J. Yang, J. Shi, Z. Wang, Y. Cheng, H. Wang, J. Org. Chem. 2013, 78, 6316-6321; g) X.-Y. Wang, X.-C. Wang, A. Narita, M. Wagner, X.-Y. Cao, X. Feng, K. Müllen, J. Am. Chem. Soc. 2016, 138, 12783-12786; h) T. Katayama, S. Nakatsuka, H. Hirai, N. Yasuda, J. Kumar, T. Kawai, T. Hatakeyama, J. Am. Chem. Soc. 2016, 138, 5210-5213.

[6] a) T. Hosokawa, Y. Takahashi, T. Matsushima, S. Watanabe, S. Kikkawa, I. Azumaya, A. Tsurusaki, K. Kamikawa, J. Am. Chem. Soc. 2017, 139, 18512-18521; b) V. Berezhnaia, M. Roy, N. Vanthuyne, M. Villa, J.-V. Naubron, J. Rodriguez, Y. Coquerel, M. Gingras, J. Am. Chem. Soc. 2017, 139, 18508-18511.

[7] T. Fujikawa, Y. Segawa, K. Itami, J. Am. Chem. Soc. 2016, 138, 3587-3595.

[8] H. Tanaka, Y. Kato, M. Fujiki, Y. Inoue, T. Mori, J. Phys. Chem. A 2018, 122, 7378-7384. 
[9] a) J. Griffiths, Colour and constitution of organic molecules, Academic press, 1976; b) J. Fabian, $\mathrm{H}$. Hartmann, Light absorption of organic colorants: theoretical treatment and empirical rules, Vol. 12, Springer Science \& Business Media, 2013; c) K. Nishimoto, Bull. Chem. Soc. Jap. 1993, $66,1876-1880$.

[10] a) L. Rulíšek, O. Exner, L. Cwiklik, P. Jungwirth, I. Starý, L. Pospíšil, Z. Havlas, J. Phys. Chem. C 2007, 111, 14948-14955; b) Y. Nakai, T. Mori, Y. Inoue, J. Phys. Chem. A 2012, 116, 7372-7385.

[11] T. Mori, Chem. Rev. 2021, 121, 2373-2412.

[12] a) I. Pozo, E. Guitián, D. Pérez, D. Peña, Acc. Chem. Res. 2019; b) E. Guitián, D. Pérez, D. Peña, in Palladium in Organic Synthesis, Springer, 2005, pp. 109-146.

[13] W. Sun, X. Tang, J. Li, M. He, R. Zhang, X. e. Han, Y. Zhao, Z. Ni, Tet. Lett. 2020, 61, 151467.

[14] a) M. S. Newman, J. Org. Chem. 1951, 16, 860-862; b) T. Okamoto, K. Shudo, N. Miyata, Y. Kitahara, S. Nagata, Chem. Pharm. Bull. 1978, 26, 2014-2026; c) N. T. Nashed, A. Bax, R. J. Loncharich, J. M. Sayer, D. M. Jerina, J. Am. Chem. Soc. 1993, 115, 1711-1722; d) B. L. Vanduuren, G. Witz, S. C. Agarwal, J. Org. Chem. 1974, 39, 1032-1035; e) D. H. R. Barton, P. G. Sammes, G. G. Weingarten, J. Chem. Soc. C 1971, 729-736.

[15] A. van der Ham, H. S. Overkleeft, D. V. Filippov, G. Schneider, Eur. J. Org. Chem. 2021, 20132017.

[16] D. Peña, A. Cobas, D. Pérez, E. Guitián, L. Castedo, Org. Lett. 2000, 2, 1629-1632.

[17] We initially started by modelling the trimerization of benzyne as a model reaction, the results of which are provided in the Supporting Information.

[18] a) T. Hosokawa, T. Asada, K. Kamikawa, J. Phys. Chem. A 2020, 124, 652-661; b) T. Hosokawa, A. Tsurusaki, K. Kamikawa, J. Synth. Org. Chem. Jap. 2020, 78, 1013-1020.

[19] A. M. Kluwer, C. J. Elsevier, M. Bühl, M. Lutz, A. L. Spek, Angew. Chem. Int. Ed. 2003, 42, 35013504.

[20] M. Retbøll, A. J. Edwards, A. D. Rae, A. C. Willis, M. A. Bennett, E. Wenger, J. Am. Chem. Soc. 2002, 124, 8348-8360.

[21] This geometrical feature is observed when using both $\omega B 97 X-D$ and PBE-D3(BJ) functionals. When no dispersion correction is used (B3LYP) the aryne ring is centered on the Pd atom, i.e. yielding a $D_{2}$ symmetry in the case of benzyne. Although not directly comparable, a similar non-symmetrical structure was found for the $\mathrm{V}^{+}\left(\mathrm{C}_{4} \mathrm{H}_{4}\right) \cdots\left(\mathrm{C}_{2} \mathrm{H}_{2}\right)$ complex both experimentally (IR) and computationally (B3LYP/def2TZVP). See Marks et al. J. Phys. Chem. A 2019, 123, 31, 6733-6743.

[22] H. Kubo, T. Hirose, K. Matsuda, Org. Lett. 2017, 19, 1776-1779.

[23] A. Jenard-De Koninck, N. Defay, R. De Ridder, Bull. Soc. Chim. Belges 1960, 69, 558-562.

[24] L. G. Wade, Organic chemistry. Englewood Cliffs, NJ: Prentice Hall 1991, 667-712. 


\section{TOC}

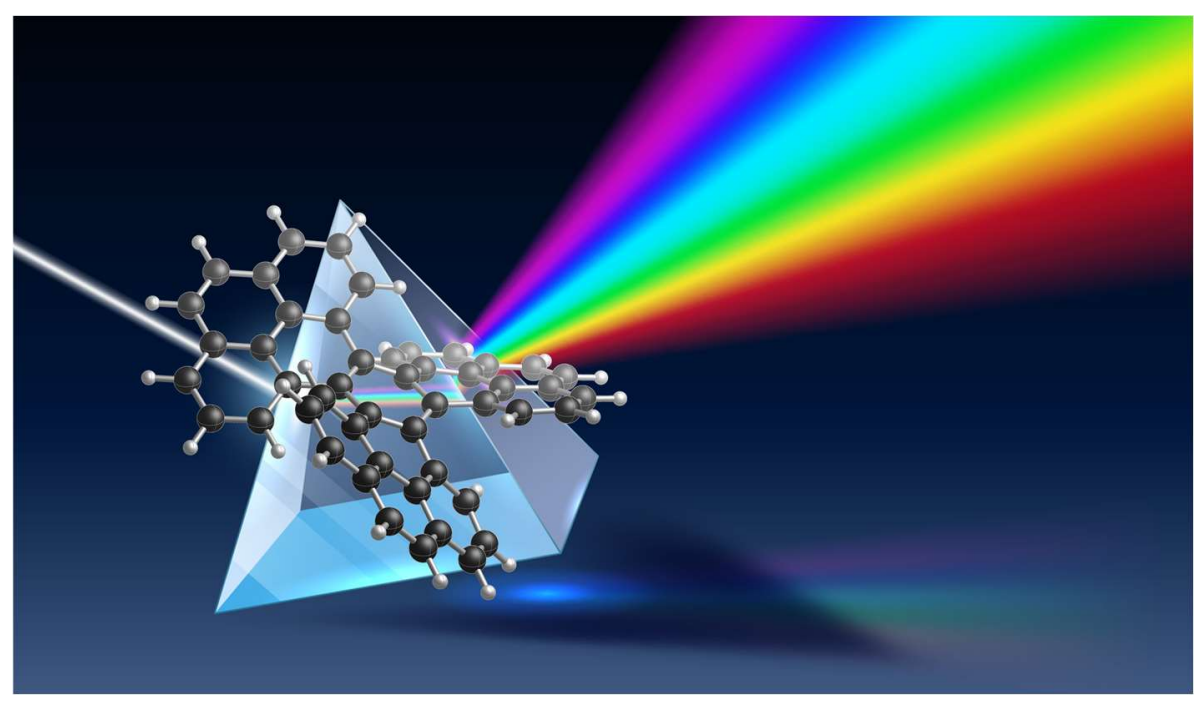

Propellerenes in the limelight! The way propellerenes interact with light is engrained in their structure. A proper understanding of the relationship between the two is thus vital for their rational design. We found the helical motives to dominate their physico-chemical properties, which is modulated by extension of the $\pi$-conjugated system. 